\title{
Biological lattices in fast self-repair mechanisms in plants and the development of bio-inspired self-healing polymers
}

\author{
G. Bauer ${ }^{1}$, A. Nellesen ${ }^{2} \&$ T. Speck ${ }^{1,3}$ \\ ${ }^{I}$ Plant Biomechanics Group Freiburg, Botanic Garden, \\ Faculty of Biology, University of Freiburg, Germany \\ ${ }^{2}$ Fraunhofer Institute UMSICHT, Oberhausen, Germany \\ ${ }^{3}$ Competence Networks Biomimetics and BIOKON, Germany
}

\begin{abstract}
Polymers are often used in fields of application with high mechanical loads. Thereby, micro-cracks, which can exist in every component, may grow up to overcritical lengths. Thus, components may fail even far below the maximum critical load. Equipping these components with self-healing capabilities is a smart way of preventing them from failure, as healing the micro-cracks may inhibit or at least decelerate crack expansion. The ability of self-healing is common in many plant species. For example, the initial tensile strength of uninjured bark of Ficus benjamina is partly restored after injury by self-repair due to the secretion and coagulation of latex. Several tests such as infrared spectroscopy and analyses of the duration and pressure dependency of latex coagulation were conducted, as shown in a case study for $F$. benjamina. These tests will also be used in a standardized way for a comparison of the coagulation mechanisms of different latex-bearing plants. The biological self-healing mechanisms will serve as role models for a transfer into bio-inspired technical self-healing materials.
\end{abstract}

Keywords: self-healing, polymers, biomimetics, Ficus benjamina, latex coagulation. 


\section{Introduction}

The ability to heal fissures and lesions without extrinsic intervention is widely spread among plants. One biomimetic approach to transfer such a self-healing ability into technical applications has successfully been realized by developing self-repairing foams for pneumatic technical structures (Speck et al. [1], Speck et al. [2]). In that case turgescent cellular plant structures that seal and repair fissures caused by internal growth processes or external lesions served as a role model. Other technical self-healing materials were developed, partly inspired from biological mechanisms (Yuan et al. [3], Trask et al. [4]). As an example, compartmentalized systems were used, in which micro capsules (White et al. [5]) or hollow fibres/micro tubes (Pang and Bond [6], Dry [7]) filled with a healing agent were embedded in a polymer matrix. Upon injury, the healing agents are released, enter the lesion, polymerize, cure and thus heal the damage. Another attempt was to embed vascular self-healing systems into technical materials (Kim et al. [8], Toohey et al. [9]). However, as the mentioned self-healing strategies are not efficient enough or applicable for all technical polymers, an enhancement of these systems is desirable. Our research focuses on polymers that are used in applications subjected to heavy mechanical loads. Micro-cracks that exist in nearly every component may lead to failure of components even below their maximum critical load, as they grow to overcritical lengths under cyclic loading. Self-healing strategies found in nature may thus serve as concept generators for biomimetic self-healing elastomers that stop or even heal micro-cracks. Plant secretions, such as resins and particularly lattices, are suitable as role models (Bauer et al. [10]). Upon injury of a latex bearing plant, this healing agent is discharged and results in closure of the wound by coagulation. In the case of Hevea brasiliensis the mechanism of latex coagulation was described by d'Auzac et al. [11]. He suggests a pressuredependent release of the protein Hevein upon injury that cross-links rubber particles, and thus leads to latex coagulation. A comparison of the coagulation mechanisms of several latex bearing plant species may reveal similarities or differences among them allowing one to adjust technical self-healing systems under various conditions. Several experiments were carried out in a case study with the Weeping Fig (Ficus benjamina) in order to set up a standardized basis to extend these experiments to further plant species from different families. These experimental analyses comprised pressure dependence and duration of latex coagulation, infrared spectroscopy of latex and tensile tests of the bark.

\section{Materials and methods}

The latex of Ficus benjamina (Moraceae), Euphorbia amygdaloides var. robbiae, Euphorbia characias, Euphorbia myrsinites (Euphorbiaceae), Campanula latifolia, Campanula glomerata (Campanulaceae), Vinca major and Vinca minor (Apocynaceae) was gathered by tapping the stems of fresh plant material. 
To analyze changes in chemical bonds during latex coagulation, infrared spectroscopy (Brukeroptics Vertex 70) with attenuated total reflection was applied to latex samples during the process of coagulation. Here, the measuring beam penetrates the sample up to a certain depth, gets attenuated due to interactions with covalent bonds within the sample and then gets reflected (ATR). The measurements were started immediately after the fresh latex samples were spread on the experimental setup.

The duration of latex coagulation was characterized by macroscopic observations (changes in latex transparency) and changes in viscosity. The pressure dependence of latex coagulation was tested with a self-built pressure box (fig. 1), where fresh stem segments were injured under a constant pressure ranging from 1 to 9 bar. The experimental setup included a removable plexiglass cover allowing one to observe the coagulation process. After a stem segment was inserted into the box, the pressure was raised and the stem segment was injured by a rotatable blade. The box was opened as soon as a change in latex transparency could be observed. The latex was constituted as coagulated when both a change in transparency and in viscosity had occurred.

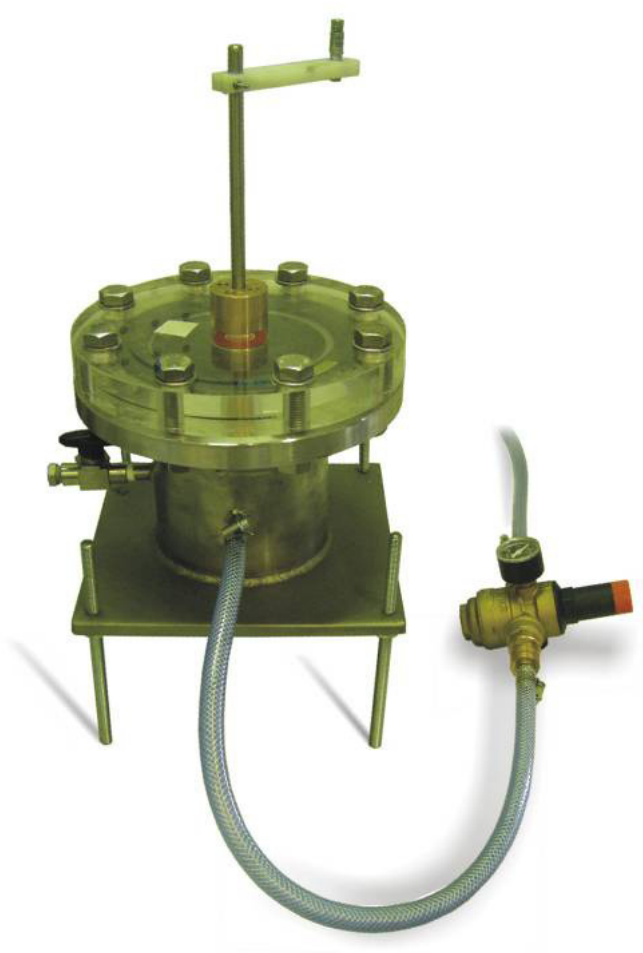

Figure 1: Pressure box for testing the pressure dependence of latex coagulation. 
Tensile tests of both injured and uninjured bark were conducted to examine the recovery of biomechanical properties after injury. Bark samples of stem segments were prepared and tested with an Inspekt retrofit (Hegewald and Peschke). Injured bark samples were either tested immediately after injury or after a latency time of $35 \mathrm{~min}$. Tests were evaluated only if samples were not ripped apart at the experimental setup clamps.

\section{Results and discussion}

Macroscopic observations reveal changes in latex viscosity and latex transparency as the milky-white fresh latex turns transparent during coagulation. The time span until the initiation of these changes significantly differs between two groups of plants examined: the latex of two Campanula species coagulates after two to seven seconds, whereas it takes up to 20 min for latex from Vinca, Euphorbia and Ficus. For example, in the case of Ficus benjamina, first changes can be observed after more than 6 minutes (fig. 2). This result fits infraredspectroscopic (IR) measurements of $F$. benjamina latex during coagulation, which reveals greatest changes in the spectra in a time slot between 6 and $10 \mathrm{~min}$ after injury (fig. 3).

These changes mainly concern a decrease of water caused by evaporation and an increasing amount of amide bonds. Further observations (data not shown here) show that this increase is not related to effects like sedimentation of

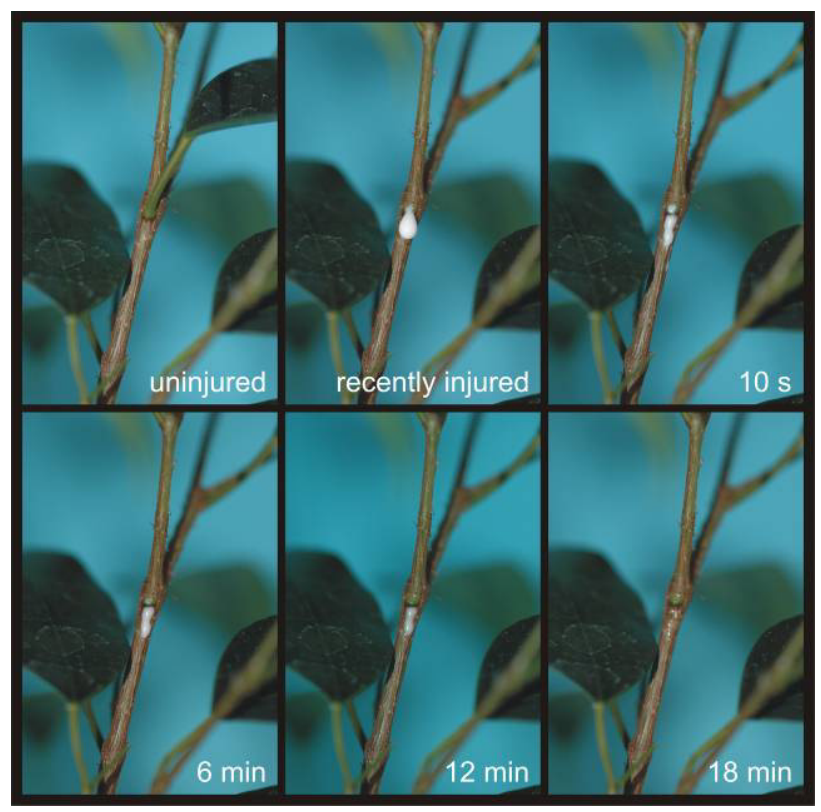

Figure 2: Coagulation of Ficus benjamina latex after injury. 


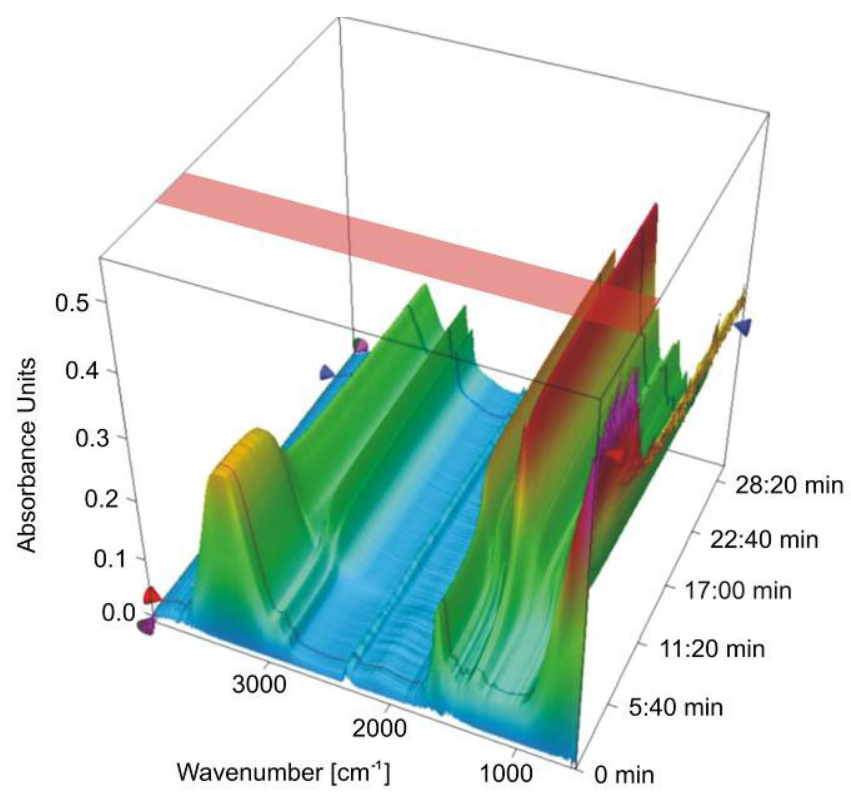

Figure 3: $\quad$ IR-spectrum of coagulating Ficus benjamina latex.

proteins but to the formation of new covalent amide bonds. Thus the theory of d'Auzac et al. [11], suggesting the formation of new protein bonds between latex particles to cause the coagulation of Hevea brasiliensis latex, can be supported also for $F$. benjamina.

When $F$. benjamina latex is injured at a pressure of 1 to $2 \mathrm{bar}$, the coagulation time does not differ from that under ambient conditions. Above a pressure of 2 bar the coagulation time augments promptly and drastically to several hours. The remarkable pressure dependency of the coagulation process indicates that the coagulation theory of d'Auzac et al. [11] mentioned above is valid for $F$. benjamina as well. As the pressure in $H$. brasiliensis laticiferous phloem tissues is known to be in the range between about 7 and 15 bar (Buttery and Boatman [12]) and previous observations revealed a pressure of more than 8 bar in the laticifers in $F$. benjamina (data not shown here), the conditions of these two systems are comparable concerning the pressure dependency of latex coagulation.

Tensile tests of injured bark of $F$. benjamina reveal that biomechanical properties could be restored at least partly. The tensile strength of bark samples increases with the time after injury (fig. 4) even though the tensile strength cannot be restored to that of uninjured bark within a time slot of 35 minutes. Due to tensile tests the self-healing ability of plants may be quantified as external lesions of the bark are a common event of damage.

The experiments described in this paper outline an experimental approach to quantify the self-healing ability of latex bearing plants and represent the basis for an interspecific comparison of latex coagulation mechanisms. 


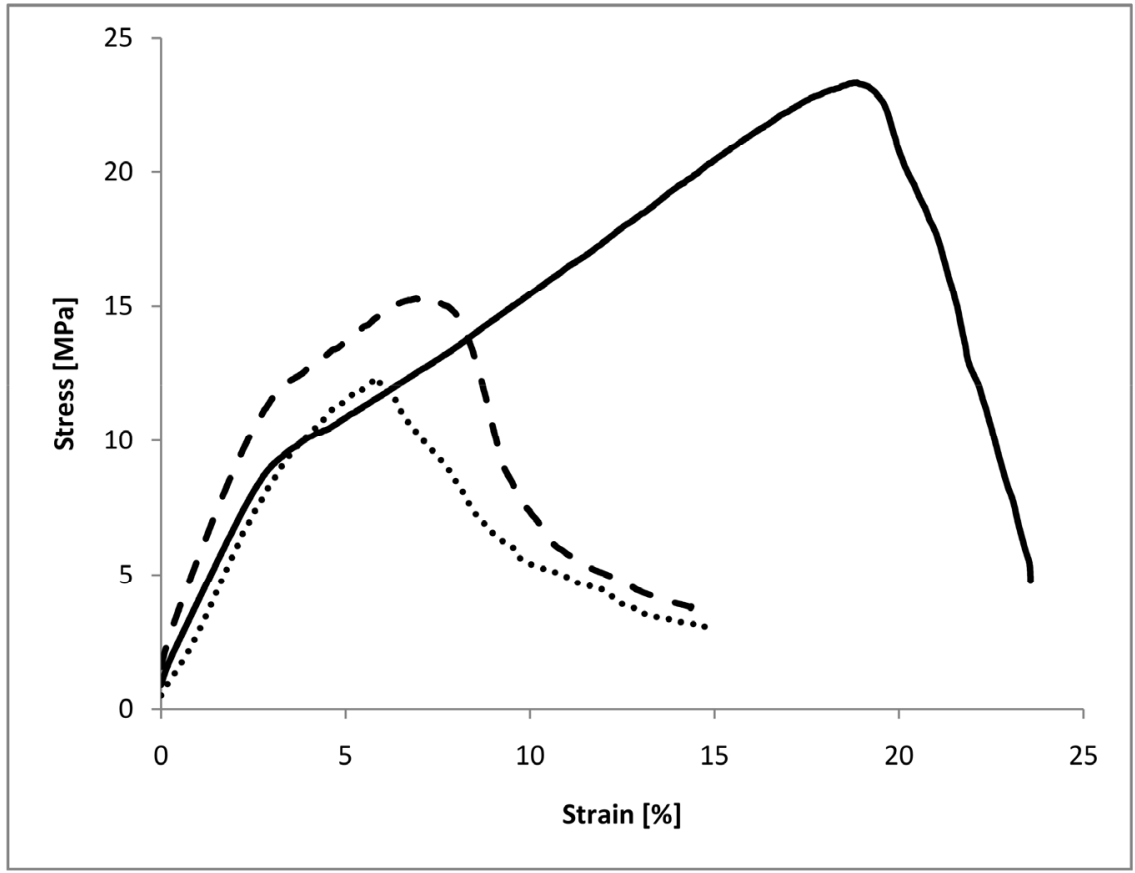

Figure 4: $\quad$ Tensile strength of uninjured bark (solid line), recently injured bark (dotted line) and of bark 35 min after injury (dashed line).

\section{Acknowledgements}

The studies presented here are part of the project 'Self-healing polymers "OSIRIS" (Selbstheilende Polymerwerkstoffe "OSIRIS"), which is funded within the scope of the funding directive BIONA by the German Federal Ministry of Education and Research. We also thank our research partners for assistance and many helpful discussions.

\section{References}

[1] Speck, T., Luchsinger, R., Busch, S., Rüggeberg, M. \& Speck, O., Selfhealing processes in nature and engineering: self-repairing biomimetic membranes for pneumatic structures. Design and Nature III, ed. C.A. Brebbia, WIT Press: Southampton, pp. 105 - 114, 2006.

[2] Speck, O., Luchsinger, R., Busch, S., Rüggeberg, M. \& Speck, T., Selfrepairing membranes for pneumatic structures: transferring nature's solutions into technical applications. Proceedings of the 5th International Plant Biomechanics Conference Vol. I, ed. L. Salmen, STFI Packforsk AB: Stockholm, pp. 115 - 120, 2006. 
[3] Yuan, Y.C., Yin, T., Rong, M.Z. \& Zhang, M.Q., Self healing in polymers and polymer composites. Concepts, realization and outlook: A review. eXPRESS Polymer Letters, 2, pp. 238-250, 2008.

[4] Trask, R.S., Williams, H.R. \& Bond, I.P., Self-healing polymer composites: mimicking nature to enhance performance. Bioinsp. Biomim., 2, pp. 1-9, 2007.

[5] White, S.R., Sottos, N.R., Geubelle, P.H., Moore, J.S., Kessler, M.R., Sriram, S.R., Brown, E.N. \& Viswanathan, S., Autonomic healing of polymer composites. Nature, 409, pp. 794-797, 2001.

[6] Pang, J.W.C. \& Bond, I.P., 'Bleeding composites'-damage detection and self-repair using a biomimetic approach. Composites $A, \mathbf{3 6}$, pp. 183-188, 2005.

[7] Dry, C., Procedures developed for self-repair of polymer matrix composite materials. Composite Structures, 35, pp. 263-269, 1996.

[8] Kim, S., Lorente, S. \& Bejan, A., Vascularized materials, Tree-shaped flow architectures matched canopy to canopy. J. Apl. Phys., 100, pp. 063525-1063525-8, 2006.

[9] Toohey, K.S., Hansen, C.J., Lewis, J.A., White, S.R. \& Sottos N.R., Delivery of Two-Part Self-Healing Chemistry via Microvascular Networks. Adv. Funct. Mater., 19, pp. 1399-1405, 2009.

[10] Bauer, G., Nellesen, A., Sengespeick, A. \& Speck, T., Fast self-repair mechanisms in plants: biological latices as role models for the development of biomimetic self-healing, mechanically loaded polymers. Proceedings of the 6th Plant Biomechanics Conference, ed. B. Thibaut, ECOFOG: Cayenne, pp. 367-373, 2009.

[11] d'Auzac, J., Prevot, J.-C. \& Jacob, J.-L., What's new about lutoids? A vacuolar system model from Hevea latex. Plant physiology and biochemistry. 33, pp. 765-777, 1995.

[12] Buttery, B.R. \& Boatman, S.G., Manometric Measurement of Turgor Pressures in Laticiferous Phloem Tissues. Journal of Experimental Botany 17(2), pp. 283-96, 1966. 